\title{
Kuwanon G protects HT22 cells from advanced glycation end product-induced damage
}

\author{
WEN-JUN GAN ${ }^{1 *}$, CHEN-LIN GAO $^{1,2^{*}}$, WEN-QIAN ZHANG ${ }^{1}$, JUN-LING GU ${ }^{1}$, TING-TING ZHAO ${ }^{1}$, \\ HENG-LI GUO ${ }^{1}$, HUA ZHOU ${ }^{1}$, YONG XU ${ }^{2}$, LI-LI YU ${ }^{1}$, LI-FANG LI ${ }^{1}$, DING-KUN GUI ${ }^{3}$ and YOU-HUA XU ${ }^{1}$ \\ ${ }^{1}$ Faculty of Chinese Medicine, State Key Laboratory of Quality Research in Chinese Medicine, \\ Macau University of Science and Technology, Taipa, Macao SAR 999078; \\ ${ }^{2}$ Department of Endocrinology, Affiliated Hospital of Southwest Medical University, Luzhou, Sichuan 510500; \\ ${ }^{3}$ Department of Nephrology, Shanghai Jiaotong University Affiliated Sixth People's Hospital, Shanghai 200233, P.R. China
}

Received January 31, 2019; Accepted September 11, 2020

DOI: $10.3892 /$ etm.2021.9869

\begin{abstract}
The incidence of diabetic encephalopathy is increasing as the population ages. Evidence suggests that formation and accumulation of advanced glycation end products (AGEs) plays a pivotal role in disease progression, but limited research has been carried out in this area. A previous study demonstrated that Kuwanon G (KWG) had significant anti-oxidative stress and anti-inflammatory properties. As AGEs are oxidative products and inflammation is involved in their generation it is hypothesized that KWG may have effects against AGE-induced neuronal damage. In the present study, mouse hippocampal neuronal cell line HT22 was used. KWG was shown to significantly inhibit AGE-induced cell apoptosis in comparison with a control treatment, as determined by both MTT and flow cytometry. Compared with the AGEs group, expression of pro-apoptotic protein $\mathrm{Bax}$ was reduced and expression of anti-apoptotic protein Bcl-2 was increased in the AGEs + KWG group. Both intracellular and extracellular levels of acetylcholine and choline acetyltransferase were significantly elevated after KWG administration in comparison with controls whilethe level of acetylcholinesterase decreased. These changes in
\end{abstract}

Correspondence to: Dr Ding-Kun Gui, Department of Nephrology, Shanghai Jiaotong University Affiliated Sixth People's Hospital, Haigang Avenue 500, Pudong New Area, Shanghai 200233, P.R. China

E-mail: dingkungui@alu.fudan.edu.cn

Dr You-Hua Xu, Faculty of Chinese Medicine, State Key Laboratory of Quality Research in Chinese Medicine, Macau University of Science and Technology, Avenida Wai Long, Taipa, Macao SAR 999078, P.R. China

E-mail:yhxu@must.edu.mo

${ }^{*}$ Contributed equally

Key words: acetylcholine, advanced glycation end products, diabetes, encephalopathy, Kuwanon G protein expression were accompanied by increased levels of superoxide dismutase and glutathione peroxidase synthesis and reduced production of malondialdehyde and reactive oxygen species. Intracellular signaling pathway protein levels were determined by western blot and immunocytochemistry. KWG administration was found to prevent AGE-induced changes to the phosphorylation levels of Akt, IкB- $\alpha$, glycogen synthase kinase 3 (GSK3)- $\alpha$ and $\beta$, p38 MAPK and NF- $\mathrm{KB}$ p65 suggesting a potential neuroprotective effect of KWG against AGE-induced damage was via the $\mathrm{PI} 3 \mathrm{~K} / \mathrm{Akt} / \mathrm{GSK} 3 \alpha \beta$ signaling pathway. The findings of the present study suggest that KWG may be a potential treatment for diabetic encephalopathy.

\section{Introduction}

Diabetic encephalopathy is one of the major chronic complications of diabetes mellitus (DM) (1). Symptoms of diabetic encephalopathy include slow reaction times, cognitive and memory dysfunction, severe cerebral thrombosis, stroke and Alzheimer's disease. Although the pathogenesis of diabetic encephalopathy is not fully understood, recent evidence suggestes that the formation and accumulation of advanced glycation end products (AGEs) plays a pivotal role. Acetylcholine (ACh) is important for the maintenance of central nervous system function (2). A study found that a reduced level of ACh may contribute to impaired learning and memory in diabetic rats (3).

Oxidative stress has a close relationship with the development of DM and diabetic encephalopathy (4). It has been demonstrated that ROS are a class of highly reactive free radical molecules that can directly damage cell viability and function (5), and that malondialdehyde (MDA) is one of the most important products of membrane lipid peroxidation and that its production can aggravate membrane damage (6). Superoxide dismutase (SOD) is an important antioxidant enzyme in organisms that can scavenge free radical molecules and glutathione peroxidase (GPX) is a peroxide-degrading enzyme widely distributed in organisms that can catalyze the reduction of toxic peroxides into non-toxic hydroxy compounds thus protecting the structure and function of cell 
membranes against peroxide damage $(7,8)$. To comprehensively evaluate effects of KWG against oxidative stress, the above parameters were determined. It has also been demonstrated that high concentrations of flavonoids are cytotoxic (9). On the other hand, cell death is closely related with production of ROS (10). Cortex Mori [CM; Cortex Mori is the dry root bark of Morus alba (Latin scientific name, Morus alba L.)] is a traditional Chinese medicine believed to be beneficial in the treatment of DM. A previous study found that CM extract had an antidepressant-like effect on the rat hippocampus (11). Flavonoids have been widely reported to increase cell viability $(12,13)$ and they are the main components of CM (14). Several studies have demonstrated the antiinflammatory, antioxidant and hypoglycemic effects of flavonoids from CM (15-17), but the specific molecule behind these effects is unknown. In a previous study, Kuwanon G (KWG), a flavonoid derived from CM, was suggested to have a beneficial effect against lipopolysaccharide-induced inflammation and oxidative stress (12). The antiinflammatory effect of KWG has been demonstrated by a number of research groups $(9,18,19)$.

The HT22 cell line is a mouse hippocampal neuron cell line. This cell line is a good model for studying the toxicity of glutamate in vitro, and has good applications in many neurodegenerative diseases, such as Alzheimer's and Parkinson's disease $(20,21)$. Therefore, HT22 cells were selected for the present study.

In the present study, the neuroprotective effects of KWG were explored in an in vitro model of a high glucose environment and the potential mechanisms underlying its action were investigated.

\section{Materials and methods}

Materials. Kuwanon G (Fig. 1A) was supplied by Chengdu Pufeide Biotech Co., Ltd. AGEs were prepared by incubating bovine serum albumin (BSA; Gibco; Thermo Fisher Scientific, Inc.) with $50 \mathrm{mM}$ D-glucose (GBCBIO Technologies, Inc.) under sterile conditions in $5 \% \mathrm{CO}_{2} / 95 \%$ air at $37^{\circ} \mathrm{C}$ for 3 months. Unincorporated glucose was then removed by dialysis overnight against $0.01 \mathrm{M}$ phosphate-buffered saline (PBS). Unmodified BSA was incubated in the absence of glucose under the same conditions, to be used as a control. AGEs were stored at $4^{\circ} \mathrm{C}$ until use (22-24). Primary antibodies against Akt (cat. no. sc-514032), phosphorylated (p)-Akt (cat. no. sc-8312), IкB- $\alpha$ (cat. no. sc-1643), p-ІкB- $\alpha$ (cat. no. sc-8404), glycogen synthase kinase 3 (GSK3) $\alpha / \beta$ (cat. no. sc-7291), p-GSK $3 \alpha / \beta$ (cat. no. sc-81496), GAPDH (cat. no. sc-47724) and RIPA Lysis Buffer (cat. no. sc-24948) were supplied by Santa Cruz Biotechnology, Inc. Antibodies for p38 MAPK (cat. no. 8690S), p-p38 MAPK (cat. no. 9216S),

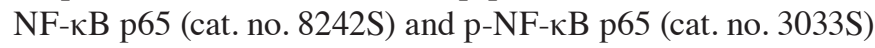
were from Cell Signaling Technology, Inc. Bcl-2 (cat. no. bs-0032R) and Bax (cat. no. bs-0127R) primary antibodies, FITC- (cat.no. bs-0295D-FITC), Cy3- (cat.no.bs-0296G-Cy3), goat anti-rabbit IgG/FITC (cat. no. bs-0295G-FITC) and goat anti-mouse IgG/FITC (cat. no. bs-0296G-FITC) conjugated secondary antibodies were bought from BIOSS. The ELISA kit for ACh (cat. no. KTE70539) was purchased from Abbkine Scientific Co,. Ltd. DAPI (cat. no. C1002) was supplied by GBCBIO Technologies, Inc. An Annexin V-propidium iodide
(AV-PI) kit (cat. no. KGA101) was purchased from Nanjing KeyGen Biotech Co., Ltd. Glutathione peroxidase (GPX; cat. no. S0056) and intracellular reactive oxygen species (ROS; cat. no. S0033S) detection kits were supplied by Beyotime Institute of Biotechnology. Superoxidase dismutase (SOD; cat. no. A001-3-2) and choline acetyltransferase (ChAT) kits (cat. no. A079-1-1) were supplied by Nanjing Jiancheng Bioengineering Institute. Kits for malondialdehyde (MDA; cat. no. BC0025) and acetylcholinesterase (AChE; cat. no. BC2025) were purchased from Beijing Solarbio Science \& Technology Co., Ltd. Dulbecco's modified Eagle's medium (DMEM), fetal bovine serum (FBS), rabbit serum, penicillinstreptomycin Solution and trypsin were obtained from Gibco (Thermo Fisher Scientific, Inc.). Precision Plus Protein ${ }^{\mathrm{TM}}$ Dual Color Standards (cat. no. 161-0374) was supplied by Bio-Rad Laboratories, Inc.

Cell Culture. The HT22 cell line was a gift from Professor Lu Ming (Nanjing Medical University, China). Cells were cultured in DMEM supplemented with $10 \%$ heat-inactivated FBS at $37^{\circ} \mathrm{C}$ in a humidified atmosphere of $5 \% \mathrm{CO}_{2} / 95 \%$ air.

Cell viability evaluation by MTT assay. HT22 cells at an exponential growth phase were seeded on flat-bottomed 96-well plates, seeding density was $4 \times 10^{4}$ cells $/ \mathrm{ml}$. Cells were treated with PBS (vehicle), AGEs, KWG or AGEs + KWG (the cells were incubated with AGEs for 30 min followed by KWG administration), as indicated for 24-48 h. Cells were then incubated with 3-(4,5-dimethylthiazol-2-yl)-2,5-diphenyl tetrazolium bromide $(5 \mathrm{mg} / \mathrm{ml})$ for $4 \mathrm{~h}$ in the cell culture incubator. Formazan was dissolved with dimethyl sulfoxide. Absorbance values at a wavelength of $490 \mathrm{~nm}$ were measured using a spectrophotometer (Tecan Group Ltd.).

AV-FITC/PI cell apoptosis detection assay. AV-PI assay was carried out to determine cell apoptosis levels. After treatment, the cells were washed twice with cold PBS, dissociated with EDTA-free trypsin (cat. no. PYG0107; Boster Biologicals) and $1 \times 10^{6}$ cells $/ \mathrm{ml}$ were harvested. A $5 \mu \mathrm{l}$ volume of AV-FITC and $10 \mu \mathrm{l}$ of PI were added sequentially. Cells were incubated in the dark at room temperature for 15 min with the stains before $400 \mu \mathrm{l}$ of binding buffer was added to the sample and the apoptosis rate measured by flow cytometry. The Q2 and Q3 quadrants were counted to determine the level of apoptosis. For this aim, BD Aria III Flow Cytometer (BD Biosciences) and the FlowJo software (7.6; FlowJo LLC) were applied for determination and analysis.

Cell anti-oxidant activity assessment. HT22 cells were seeded in 24 -well plates, seeding density was $1 \times 10^{5}$ cells $/ \mathrm{ml}$ and vehicle, Rosup (used as the positive control; Beyotime Institute of Biotechnology; cat. no. S0033S; 1:1,000), AGEs $(200 \mu \mathrm{g} / \mathrm{ml})$ or AGEs $(200 \mu \mathrm{g} / \mathrm{ml})+\mathrm{KWG}(5,30$ or $70 \mu \mathrm{M})$ were administered for $48 \mathrm{~h}$. Levels of ROS (450 nm), SOD (560 nm), GPX $(412 \mathrm{~nm})$ and MDA $(532 \mathrm{~nm})$ were determined by colorimetric assay on a plate reader according to the protocol from the product supplier.

Determination of ACh, ChAT and AChE. HT22 cells were incubated with vehicle (as a control), AGEs $(200 \mu \mathrm{g} / \mathrm{ml}$ ) or 
AGEs $(200 \mu \mathrm{g} / \mathrm{ml})+\mathrm{KWG}(5 \mu \mathrm{M})$ for $12-48 \mathrm{~h}$ as indicated; the cell culture supernatant and intracellular fluid (the intracellular fluid was obtained by lysing the cells with RIPA lysis buffer, and then collected the supernatant by centrifugation at $78,400 \times \mathrm{g}, 4^{\circ} \mathrm{C}$ for $\left.10 \mathrm{~min}\right)$ was collected to evaluate levels of Ach $(450 \mathrm{~nm})$, ChAT $(450 \mathrm{~nm})$ and AChE (450 nm) by colorimetric assay on a plate reader according to the manufacturers' protocol.

Immunofluorescence. Cells were seeded on slides in 6 -well cell culture plates (seeding density, $1.2 \times 10^{5}$ cells/ $\mathrm{ml})$ and treated with vehicle (PBS), AGEs $(200 \mu \mathrm{g} / \mathrm{ml})$ or AGEs $(200 \mu \mathrm{g} / \mathrm{ml})+\mathrm{KWG}(5 \mu \mathrm{M})$ at $37^{\circ} \mathrm{C}$ for $48 \mathrm{~h}$. After washing with cold PBS, the cells were fixed with $4 \%$ paraformaldehyde for $10 \mathrm{~min}$ at room temperature and then permeabilized with $0.25 \%$ Triton X-100. Rabbit serum (1:20; Gibco; Thermo Fisher Scientific, Inc.) was applied to block unspecific antigens for $30 \mathrm{~min}$ at $37^{\circ} \mathrm{C}$. Cells were then incubated with primary antibodies Bcl-2 (1:200), Bax

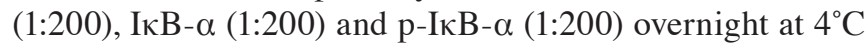
After washing with $\mathrm{PBS}$, cells were further incubated with FITC- or Cy3-conjugated secondary antibodies at $4^{\circ} \mathrm{C}$ for $12 \mathrm{~h}$. DAPI was applied for nuclear staining. Finally, images were obtained using a confocal laser scanning microscope (Olympus Corporation; magnification, x800).

Western blotting. Total protein from HT22 cells was extracted with RIPA lysis buffer (Santa Cruz Biotechnology, Inc.; cat. no. sc-24948), and the concentration was determined using Bradford assay. Proteins ( $30 \mu \mathrm{g} /$ lane) were separated by sodium dodecyl sulfate polyacrylamide gel electrophoresis minigel $(10 \%)$ and then electro-transferred onto PVDF membranes. After blocking with $5 \%$ non-fat milk for $12 \mathrm{~h}$ at $4^{\circ} \mathrm{C}$, the membranes were incubated with primary antibodies against Bcl-2 (1:1,000), Bax (1:1,000), Akt (1:1,000), p-Akt (1:1,000), p38 MAPK $(1: 1,000)$, p-p38 MAPK $(1: 1,000)$, NF-кB p65

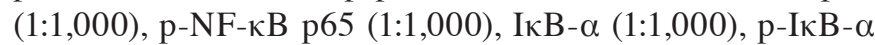
$(1: 1,000)$, GSK $3 \alpha / \beta(1: 1,000)$ or $\mathrm{p}-\mathrm{GSK} 3 \alpha / \beta(1: 1,000)$ at $4^{\circ} \mathrm{C}$ overnight and then incubated with goat anti-rabbit IgG/FITC $(1: 6,000)$ or goat anti-mouse IgG/FITC $(1: 6,000)$ horseradish peroxidase-conjugated secondary antibodies for $1 \mathrm{~h}$ at room temperature. The protein bands were visualized using a Bio-Rad Chemi Doc ${ }^{\mathrm{TM}}$ XRS system (Bio-Rad Laboratories, Inc.) and band density was measured using ImageJ software (version 1.52; National Institutes of Health). Relative expression of target proteins was calculated based on the value of the internal control GAPDH.

Statistical analysis. Data are expressed as mean \pm SD for at least 3 independent experiments. Differences between groups were analyzed by SPSS 22.0 software (IBM Corp.) using one-way ANOVA with a Tukey's post hoc test. $\mathrm{P}<0.05$ was regarded as statistically significant.

\section{Results}

$K W G$ alleviates the oxidative stress injury of HT22 cells caused by AGEs. To evaluate the influence of KWG on cell viability was assayed by MTT. AGE administration concentration-dependently induced HT22 cell death
(Fig. 1B and C), and co-incubation with 5-70 $\mu \mathrm{M}$ of $\mathrm{KWG}$ blocked this trend (Fig. 1D and E); the most significant effect of KWG was observed at $5 \mu \mathrm{M}$. However, once the concentration of KWG was higher than $70 \mu \mathrm{M}$, an inhibition effect of KWG on cell viability was shown. The above findings were further verified by flow cytometry according to Annexin V-FITC/PI double staining in HT22 cells (Fig. 1J and $\mathrm{K}$ ). The aim of the present study was to explore effects of KWG on ACh production in HT22 cells. As $400 \mu \mathrm{g} / \mathrm{ml} \mathrm{AGEs} \mathrm{was} \mathrm{found} \mathrm{to} \mathrm{have} \mathrm{significant} \mathrm{effects}$ on reducing cell viability and a large number of cells were dead. Converging from reports and previous studies, $200 \mu \mathrm{g} / \mathrm{ml}$ of AGEs were applied in the present study (25).

In the present study, AGE-induced MDA and ROS elevation was observed to be decreased by KWG treatment (Fig. 1F and G). At the same time, AGEs-induced SOD and GPX reduction was reversed by KWG treatment (Fig. $1 \mathrm{H}$ and I). At the same time, a high dose of KWG was also found to possess cytotoxic effects on viability of HT22 cells, while $5 \mu \mathrm{mol} / 1$ KWG inhibited effects of $200 \mu \mathrm{g} / \mathrm{ml}$ of AGEs on cell viability. Thus, $5 \mu \mathrm{M}$ of KWG was used in the present study.

Kuwanon $G(K W G)$ regulated expression of $B c l-2 / B$ ax proteins in AGE-treated cells. Bcl-2 family proteins play a pivotal role in modulating cell viability (26). Western blotting and immunofluorescence were used to evaluate influence of KWG on Bcl-2 family protein expression (Fig. 2A-G). The results indicated that AGE treatment significantly increased expression of pro-apoptotic Bax and decreased anti-apoptotic Bcl-2 expression in comparison with control treatment and that KWG administration was able to alleviate the AGE-induced effects.

Acetylcholine (ACh) production was increased by KWG. Reduction of Ach is believed to be responsible for brain regression disease, including diabetic encephalopathy (27-30). Intracellular and extracellular levels of ACh after AGE administration and KWG treatment were determined by ELISA kits. As indicated in Fig. 3A and B, AGEs significantly reduced ACh content within the cells compared to control and KWG administration could restore the level of ACh both in- and outside of HT22 cells. The expression of AchE and ChAT were assessed and the results showed that AGEs significantly reduced AChE content within the cells, and KWG restored the level of AChE both in- and -outside of HT22 cells (Fig. 3C and D). At the same time, KWG reduced the secretion of ChAT induced by AGEs both in- and -outside of HT22 cells (Fig. 3E and F). This finding suggests that KWG may protect against diabetic encephalopathy via increasing $\mathrm{ACh}$ production.

Effects of Kuwanon $G$ on AGEs-induced of PI3K/AKT/ GSK3 $\alpha \beta / P 38 M A P K / N F-\kappa B$ p $65 /$ I $\kappa b-\alpha$ signaling pathway in HT22 cells. In order to further explore the underlying mechanism, some intracellular signaling pathway proteins were evaluated by western blotting. As shown in Fig. 4A-K, expression and activation of AKT and I $\mathrm{BB}-\alpha$ was restored by KWG administration, while AGE induced phosphorylation of signaling proteins including GSK $3 \alpha / \beta, \mathrm{p} 38 \mathrm{MAPK}$ and $\mathrm{NF}-\kappa \mathrm{B}$ p65 was reduced by KWG. 
A<smiles></smiles>

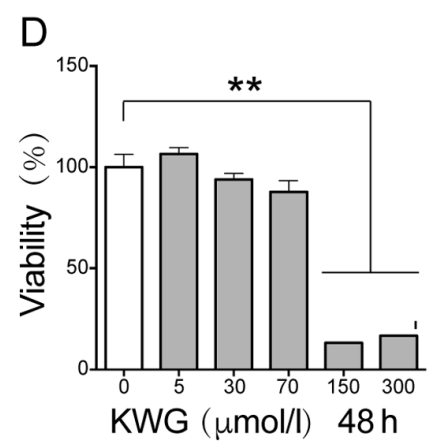

G

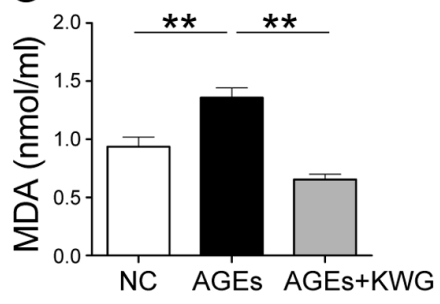

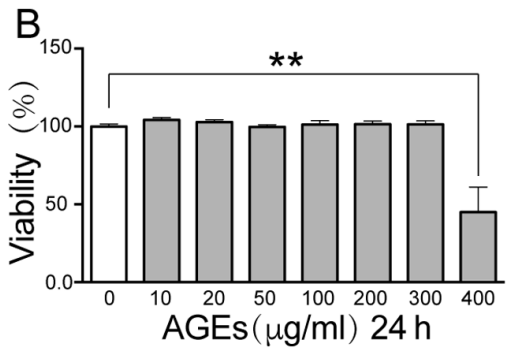

$\mathrm{E}$

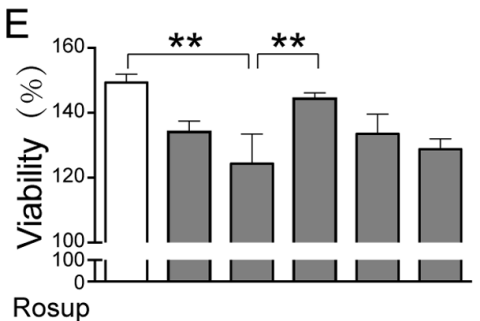

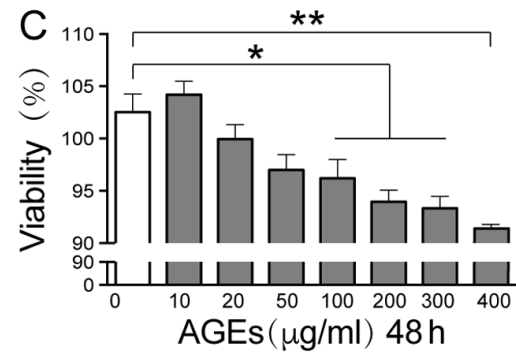

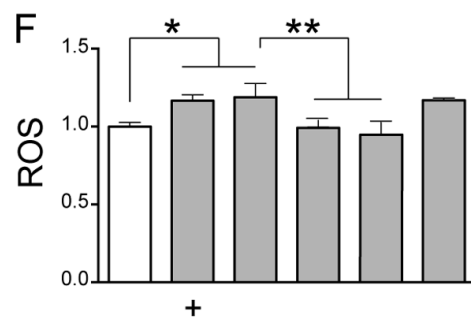

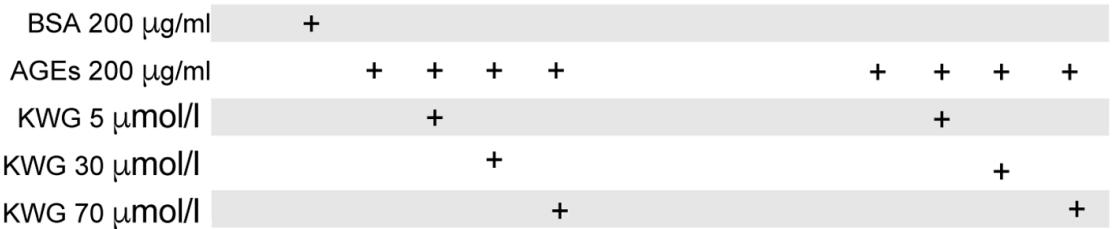

KWG 70 umol/
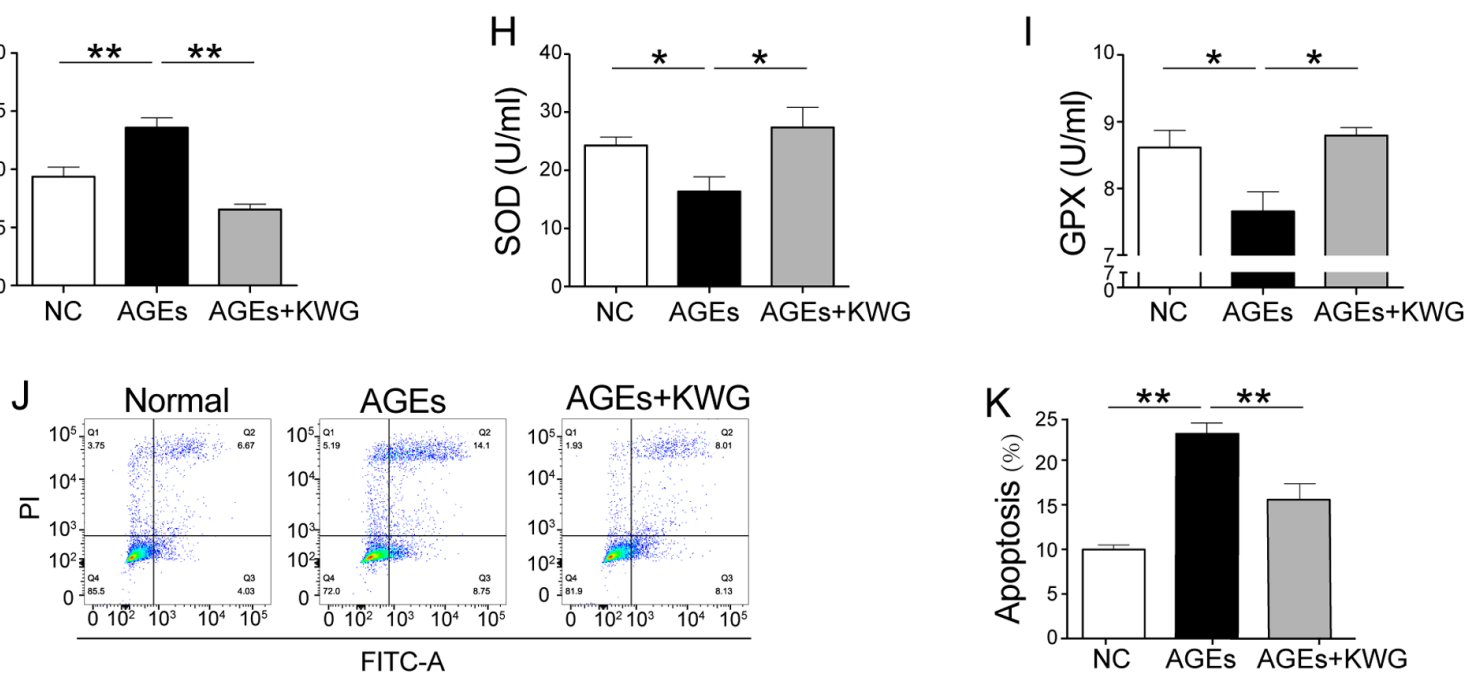

Figure 1. Effect of KWG on the viability and AGE induced-oxidative stress of HT22 cells. (A) Chemical structure of KWG. (B) Cell viability was determined by MTT after (B) 24-h and (C) 48-h AGE treatment, (D) 48-h KWG treatment and (E) after a combined treatment with AGE and KWG for Xh. (F) Levels of ROS, (G) MDA, (H) SOD and (I) GPX were assayed. (J) HT22 cell apoptosis levels were determined by flow cytometry and (K) quantified. *P<0.05, ${ }^{* *} \mathrm{P}<0.01$. AGE, advanced glycation end products; BSA, bovine serum albumin; GPX, glutathione peroxidase; KWG, kuwanon G; MDA, malondialdehyde; NC, normal control; ROS, reactive oxygen species ; SOD, superoxide dismutase.

\section{Discussion}

The diabetic population are at significant risk of developing neurodegenerative disease. Although both peripheral and central nerves can be influenced, greater focus should be on the prevention of diseases causing brain dysfunction, as cognitive and memory impairment will seriously influence patient quality of life $(25,31)$. The accumulation of AGEs has been demonstrated to contribute to diabetic encephalopathy (32). The results of the present study suggested that Kuwanon $G$ (KWG) may be able to inhibit AGE-induced neuron loss and dysfunction and the possible mechanism was also explored.

Diabetic encephalopathy is a condition closely related to both aging and hyperglycemia. Although the underlying pathophysiological mechanism of this condition remains to be elucidated, existing evidence suggests that accumulation of AGEs may be a related factor (33). AGEs refer to a group of stable metabolic products of macromolecules including proteins, amino acids, lipids or nucleic acids in the body that are glycated following exposure to sugars under non-enzymatic conditions (34-36). The two pivotal factors suggested to have a role in AGE production are hyperglycemia and oxidative stress $(37,38)$. In the present study AGEs were applied in order to construct an in vitro diabetic encephalopathy model in HT22 cells $(39,40)$, a mouse hippocampal neuron cell line commonly used to study neurodegenerative disease $(41,42)$. Reports concerning correlation between AGEs and diabetes are abundant and AGEs have been demonstrated to play a role 
A

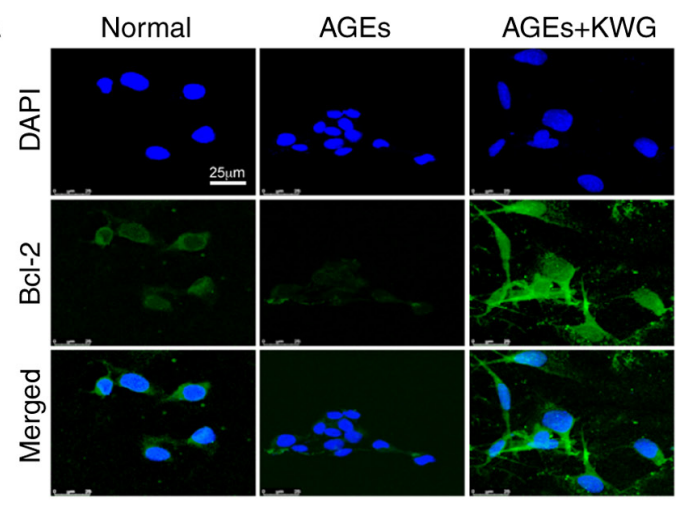

B

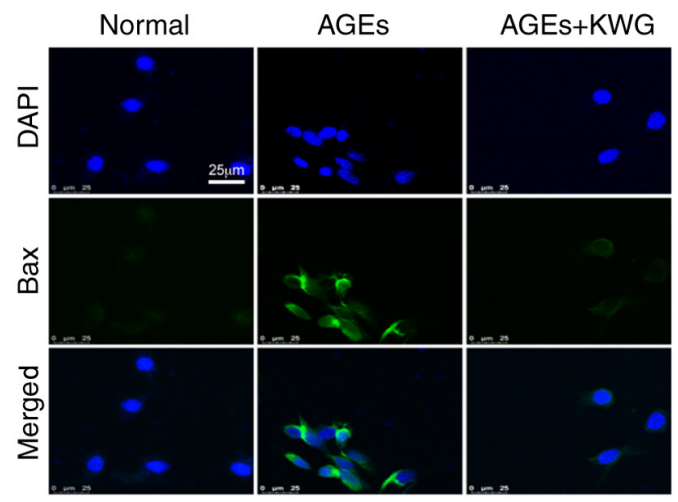

C
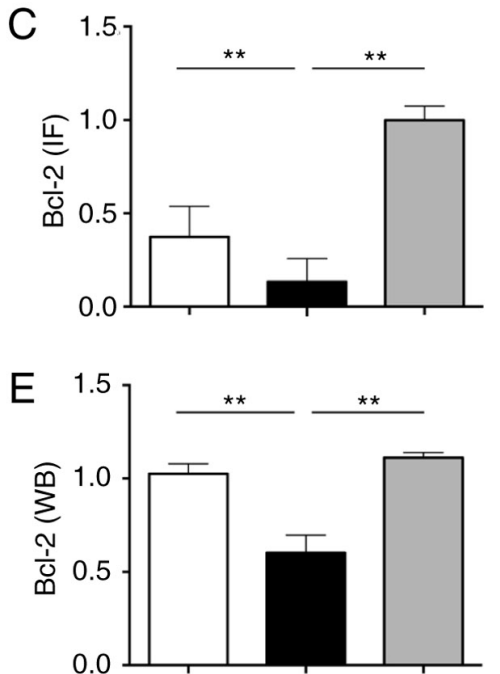

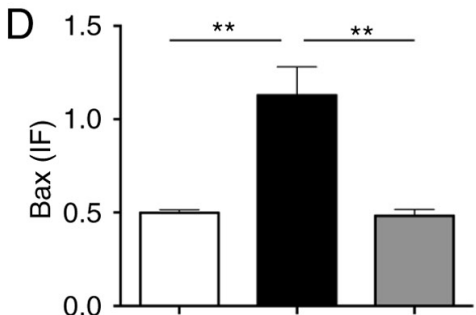

F

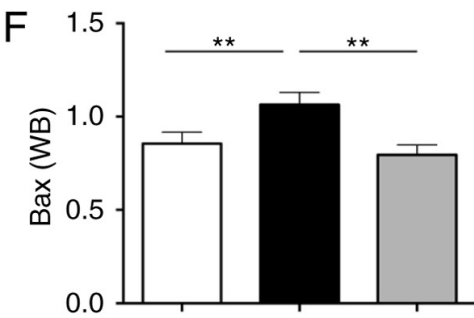

Normal

AGES

AGEs+KWG

G

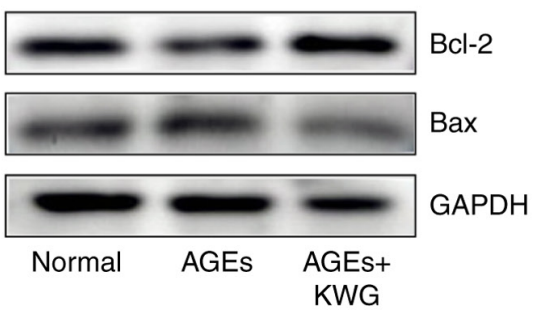

Figure 2. Expression of Bcl-2 and Bax protein was determined by immunofluorescence (magnification, $\mathrm{x} 800$ ) and western blotting. (A) Bcl-2 and (B) Bax proteins were stained using IF. (C) Bcl-2 IF quantification. (D) Bax IF quantification. (E) Bcl-2 and (F) Bax protein levels were also quantified using (G) western blot analysis. ${ }^{* *} \mathrm{P}<0.01$. AGE, advanced glycation end products; IF, immunofluorescence; KWG, kuwanon G; WB, western blotting.
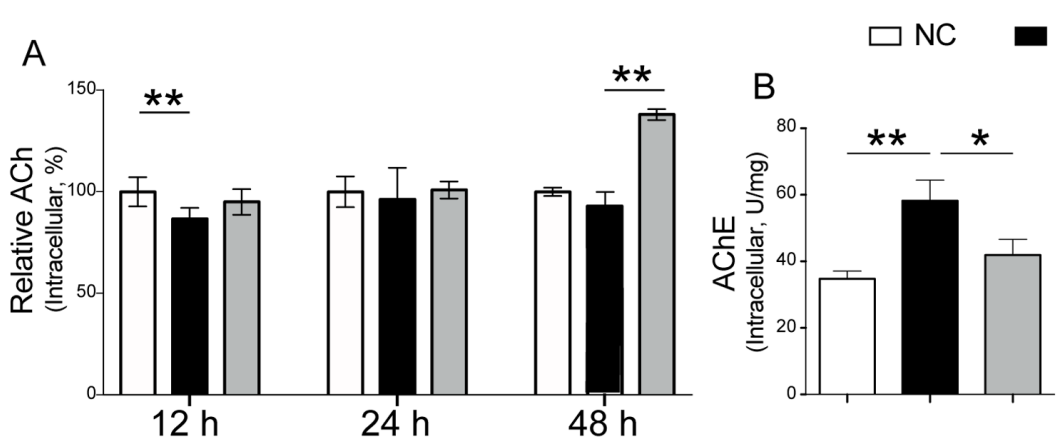

AGEs $\square$ AGEs+KWG

D

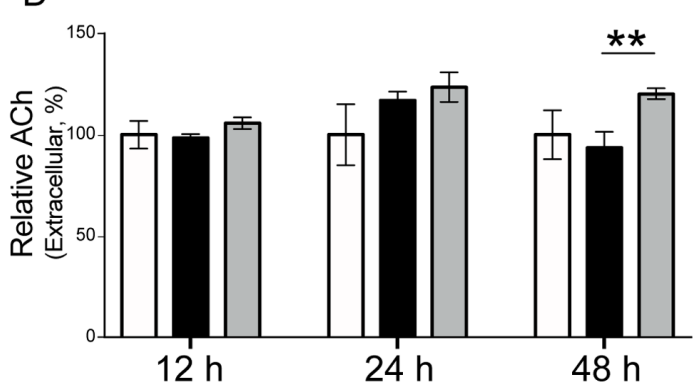

E

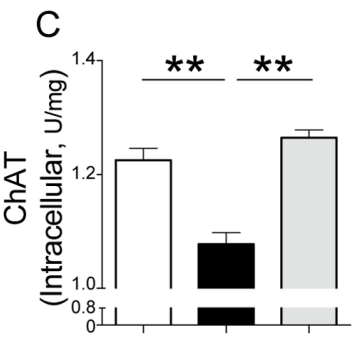

$\mathrm{F}$
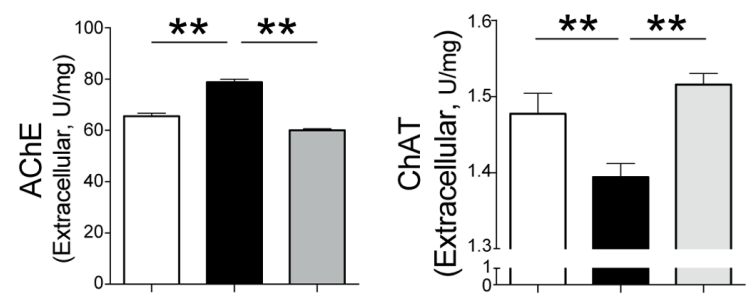

Figure 3. KWG increases ACh and ChAT production and decreases AchE secretion induced by AGEs. Intracellular levels of (A) ACh, (B) AchE and (C) ChAT after AGEs or AGE + KWG treatment were detected by an ELISA kit. Extracellular levels of (D) ACh, (E) AchE and (F) ChAT were also determined after AGEs or AGE + KWG treatment ${ }^{*} \mathrm{P}<0.05,{ }^{* *} \mathrm{P}<0.01$. ACh, acetylcholine; AChE, acetylcholinesterase; AGE, advanced glycation end products; ChAT, choline acetyltransferase; KWG, kuwanon $\mathrm{G}$; NC, normal control 

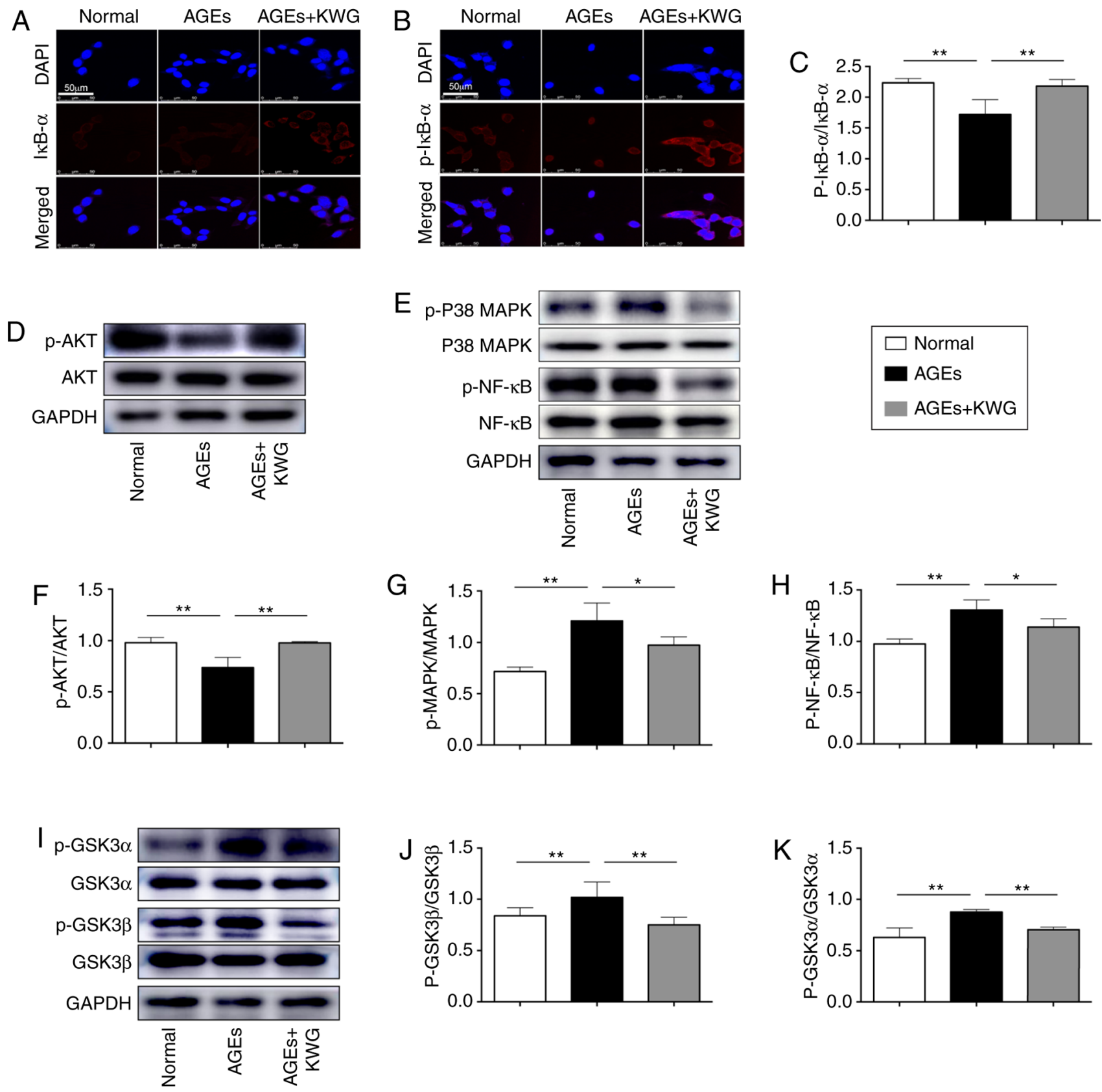

Figure 4. KWG modulates AGEs-induced signaling pathways in HT22 cells. (A) Iкb- $\alpha$ and (B) p-Iкb- $\alpha$ were detected by immunofluorescence (magnification, $\mathrm{x} 800$ ) and (C) their levels quantified. Levels of total and p-(D) Akt, (E) p38-MAPK and (F) NF-kB p65 were assessed by western blot. Levels of quantification of (F) AKT, (G) MAPK and (H) NF- $\mathrm{kB}$ p65 are shown. (I) GSK3 $\alpha$ and $\beta$ levels were also determined by western blot. Quantification of (J) GSK3 $\beta$ and (K) GSK $3 \alpha$ is shown in a graph. ${ }^{*} \mathrm{P}<0.05,{ }^{* *} \mathrm{P}<0.01$. AGE, advanced glycation end products; KWG, kuwanon $\mathrm{G}$.

in promoting diabetic neuropathy $(32,40,43)$. However, interventions specifically addressing AGEs remain very limited.

Cortex Mori (CM) is a TCM commonly thought to be beneficial in the treatment of diabetes (44-46). However, its active components are not well understood. KWG is a flavonoid that can be found in CM, but there has been limited study of its pharmacological activity. A recent finding suggested that KWG inhibited $\alpha$-glucosidase activity (14). This finding was verified by Paudel et al (9) in HepG2 cells where it was additionally shown that as well as inhibiting $\alpha$-glucosidase, KWG could also inhibit PTP1B, promote binding between insulin and the insulin receptor and alleviate insulin resistance. The above findings suggest the possibility that KWG might be a beneficial therapy for diabetes. Our previous study also demonstrated that KWG had a protective effect against diabetic endotoxemia via reducing inflammatory cytokine expression and alleviating oxidative stress (12). This supplies further evidence that KWG may have anti-inflammatory and anti-aging effects.

In the present study, the aim to was explore the potential therapeutic effect of KWG on diabetic encephalopathy. To first exclude a possibility that KWG may increase viability of HT22 cells, MTT assay was carried out. KWG at $5 \mu \mathrm{M}$ did not have significant effect on cell viability; but KWG at $5 \mu \mathrm{M}$ could inhibit effect of AGEs on reducing cell viability as well as ROS production, suggesting that KWG has an effect 
against AGE-induced cell damage. Further study found that KWG protected HT22 cells against AGE-induced damage via anti-oxidative stress and anti-inflammation related signaling pathways. Although further work remains to be carried out, the present findings support the conclusion that KWG may promote the production and secretion of $\mathrm{ACh}$ and protect hippocampal neurons from oxidative toxicity induced by AGEs.

As oxidative stress can facilitate accumulation and function of AGEs and therefore contribute to progression of neuron loss and diabetic encephalopathy (47-49), whether KWG could reduce AGE-induced ROS production was investigated. Additionally, levels of SOD, GPX and MDA were assessed and the results indicated that KWG increased the expression of SOD, GPX and reduced the secretion of MDA following AGE administration. This is in line with findings from both our group (12) and other research groups (50). Another factor that accounts for cell viability loss is apoptosis. By both flow cytometry and immunocytochemistry, it was demonstrated that KWG could inhibit HT22 cell apoptosis induced by AGEs via increasing anti-apoptotic Bcl-2 and decreasing proapoptotic Bax expressions. Preservation of cell number may inhibit progression of neurodegenerative disease.

$\mathrm{ACh}$ is a major neurotransmitter in the brain and its deficition leads to cognitive dysfunction. Dysfunction in the production and/or secretion of ACh is the basic variation that contributes to memory loss $(31,51,52)$. To evaluate whether KWG could preserve ACh levels in AGE treated HT22 cells, its content was determined by an ELISA kit. AGE administration significantly reduced the level of ACh within the cells, suggesting that accumulation of AGEs within brain tissue may promote neuro-dysfunction. Dementia and diabetes share some pathological process, including neuroinflammation, abnormal AChE levels, insulin resistance and decreased glucose metabolism (53). Studies found that during the course of diabetic encephalopathy, it was usually accompanied by decreased secretion of $\mathrm{ACh}$, and increased production of AChE $(28,54)$. The expression levels of ChAT and AChE were also assessed, and the results suggested that KWG administration could restore the level of ChAT both in- and -outside of HT22 cells following AGE treatment. At the same time, KWG reduced the secretion of AChE induced by AGEs both in- and -outside of cells. It was also observed that KWG increased the production of ChAT while inhibiting the secretion of AChE. This result shows that KWG may be beneficial in preventing the occurrence of diabetic encephalopathy.

Direct correlation between inflammation and cognitive impairment has been demonstrated in numerous studies (55-59). In diabetes, the interaction between AGE and its receptors results in the production of ROS and activation of signaling pathways, including that of p38 MAPK and NF- $\kappa \mathrm{B}(60)$. A previous study indicated that increased formation of AGEs also leads to inactivation of PI3K/AKT signaling cascade, which further activates the GSK3 pathway and promotes production of pro-inflammatory cytokines (61). Activation of GSK3 signaling pathways and oxidative stress in the brain may inhibit the expression of Bcl-2 (62). In this sense, AGEs, ROS, PI3K/AKT and MAPK activation are linked and are key contributors in the pathogenesis of diabetic cognitive dysfunction. The expression and activation of the above signaling pathway proteins was assessed in the present study. The results suggested that KWG increased the phosphorylation of AKT and $\mathrm{I} \kappa \mathrm{B}-\alpha$ and decreased the phosphorylation of GSK $3 \alpha$, GSK $3 \beta$, P38 and MAPK/NF- $\kappa$ B p65. Phosphorylation of $\mathrm{I} \kappa \mathrm{B}-\alpha$ is generally believed to be related to $\mathrm{NF}-\kappa \mathrm{B}$ p65 nuclear translocation and inflammatory events (63). In the present study, KWG administration appeared to increase activation of AKT. It has been previously demonstrated that phosphorylation of AKT will contribute to p-IкB- $\alpha$ activation (64). In the present sudy KWG increased both AKT and phosphorylation of IкB- $\alpha$, this is in line with conventional findings. However, $\mathrm{NF}-\kappa \mathrm{B}$ p65 activation was inhibited by KWG. This is obviously conflict with that of $\mathrm{p}-\mathrm{I} \kappa \mathrm{B}-\alpha$. To explain this phenomenon, activation of GSK3, which plays pivotal role in inflammation, was assessed within cells. It has been demonstrated that GSK3 plays key role in modulating $\mathrm{NF}-\kappa \mathrm{B}$ p 65 activation in that $\mathrm{p} 65$ is phosphorylated in vitro by this kinase (65), in this sense, GSK3 modulated activation of p65 after I $\mathrm{B}$. However, the underlying mechanism deserves further investigation.

One consideration is the bioavailability of KWG to neurons, i.e. its permeability across biological barriers including the blood-brain barrier (BBB). Permeability of flavonoids across the $\mathrm{BBB}$ is affected by their lipophilicity and interaction with efflux transporters. Studies from Youdim et al $(66,67)$ suggested two flavonoids, naringenin and quercetin, can cross $\mathrm{BBB}$ in vivo. Both clinical and experimental studies have also suggested that the integrity of both the gut-barrier and the BBB is damaged and that permeability of these two barriers is increased (12,66-68), suggesting that greater quantities of flavonoids may cross biological barriers under diabetic settings. However, more work should be carried out to further demonstrate this hypothesis.

In conclusion, the present study suggests that KWG can promote both the production and secretion of ACh and can protect hippocampal neurons from oxidative toxicity induced by AGEs. The present findings indicate that KWG may be a potential candidate for the prevention of diabetic neurodegenerative disease.

\section{Acknowledgements}

The authors would like to thank Professor Lu Ming from the Department of Pharmacology (Nanjing Medical University, China) for providing the HT22 cell line.

\section{Funding}

The present study was supported by the Science and Technology Development Fund of Macau (grant. no. FDCT: 0093/2018/A3).

\section{Availability of data and materials}

All data generated or analyzed during this study are included in this published article.

\section{Authors' contributions}

WJG, CLG, DKG and YHX designed the experiments. WJG, CLG, WQZ and JLG carried out the western blotting and 
immunofluorescence experiments. WJG, TTZ, HLG, LLY and LFL carried out ELISA. HZ, YX and YHX analyzed the data. WJG, CLG and YHX drafted the manuscript. HZ, YX and DKG revised the manuscript. All authors read and approved the final manuscript.

\section{Ethical approval and consent to participate}

Not applicable.

\section{Patient consent for publication}

Not applicable.

\section{Competing interests}

All authors declare that they have no competing interests.

\section{References}

1. Markowicz-Piasecka M, Sikora J, Szydłowska A, Skupień A, Mikiciuk-Olasik E and Huttunen KM: Metformin - a future therapy for neurodegenerative diseases: Theme: Drug Discovery, Development and Delivery in Alzheimer's Disease Guest Editor: Davide Brambilla. Pharm Res 34: 2614-2627, 2017.

2. Gireesh G, Kumar TP, Mathew J and Paulose C: Enhanced muscarinic M1 receptor gene expression in the corpus striatum of streptozotocin-induced diabetic rats. J Biomed Sci 16: 38, 2009.

3. Saliu JA, Oboh G, Omojokun OS, Rocha JBT, Schetinger MR, Guterries J, Stefanello N, Carvalho F, Schmatz R, Morsch VM, et al: Effect of dietary supplementation of Padauk (Pterocarpus soyauxii) leaf on high fat diet/streptozotocin induced diabetes in rats' brain and platelets. Biomed Pharmacother 84: 1194-1201, 2016.

4. Zhao J, Liu L, Li X, Zhang L, Lv J, Guo X, Chen H and Zhao T: Neuroprotective effects of an Nrf2 agonist on high glucoseinduced damage in HT22 cells. Biol Res 52: 53, 2019.

5. Waslo C, Bourdette D, Gray N, Wright K and Spain R: Lipoic acid and other antioxidants as therapies for multiple sclerosis. Curr Treat Options Neurol 21: 26, 2019.

6. Eckert GP, Eckert SH, Eckmann J, Hagl S, Muller WE and Friedland K: Olesoxime improves cerebral mitochondria dysfunction and enhances $\mathrm{A} \beta$ levels in preclinical models of Alzheimer's disease. Exp Neurol 329: 113286, 2020.

7. Balamurugan M, Santharaman P, Madasamy T, Rajesh S, Sethy NK, Bhargava K, Kotamraju S and Karunakaran C: Recent trends in electrochemical biosensors of superoxide dismutases. Biosens Bioelectron 116: 89-99, 2018.

8. Jiao Y, Wang Y, Guo S and Wang G: Glutathione peroxidases as oncotargets. Oncotarget 8: 80093-80102, 2017.

9. Paudel P, Yu T, Seong SH, Kuk EB, Jung HA and Choi JS: Protein tyrosine phosphatase $1 \mathrm{~B}$ inhibition and glucose uptake potentials of mulberrofuran G, Albanol B, and Kuwanon G from root bark of Morus alba L. in insulin-resistant HepG2 cells: An in vitro and in silico study. Int J Mol Sci 19: E1542, 2018.

10. Nourazarian AR, Kangari P and Salmaninejad A: Roles of oxidative stress in the development and progression of breast cancer. Asian Pac J Cancer Prev 15: 4745-4751, 2014.

11. Lee MS, Park WS, Kim YH, Kwon SH, Jang YJ, Han D, Morita K and Her S: Antidepressant-like effects of Cortex Mori Radicis extract via bidirectional phosphorylation of glucocorticoid receptors in the hippocampus. Behav Brain Res 236: 56-61, 2013.

12. Guo H, Xu Y, Huang W, Zhou H, Zheng Z, Zhao Y, He B, Zhu T, Tang S and Zhu Q: Kuwanon G preserves LPS-induced disruption of gut epithelial barrier in vitro. Molecules 21: E1597, 2016.

13. You S and Kim GH: Protective effect of Mori Cortex radicis extract against high glucose-induced oxidative stress in $\mathrm{PC} 12$ cells. Biosci Biotechnol Biochem 83: 1893-1900, 2019.

14. Chen Z, Du X, Yang Y, Cui X, Zhang Z and Li Y: Comparative study of chemical composition and active components against $\alpha$-glucosidase of various medicinal parts of Morus alba $\mathrm{L}$. Biomed Chromatogr 32: e4328, 2018.
15. Wei J, Chen JR, Pais EMA, Wang TY, Miao L, Li L, Li LY, Qiu F, Hu LM, Gao XM, et al: Oxyresveratrol is a phytoestrogen exerting anti-inflammatory effects through $\mathrm{NF}-\kappa \mathrm{B}$ and estrogen receptor signaling. Inflammation 40: 1285-1296, 2017.

16. Lee HJ, Lyu H, Koo U, Nam KW, Hong SS, Kim KO, Kim KH, Lee D and Mar W: Protection of prenylated flavonoids from Mori Cortex Radicis (Moraceae) against nitric oxide-induced cell death in neuroblastoma SH-SY5Y cells. Arch Pharm Res 35: 163-170, 2012.

17. Ma LL, Yuan YY, Zhao M, Zhou XR, Jehangir T, Wang FY, Xi Y and $\mathrm{Bu}$ SZ: Mori Cortex extract ameliorates nonalcoholic fatty liver disease (NAFLD) and insulin resistance in high-fat-diet/ streptozotocin-induced type 2 diabetes in rats. Chin J Nat Med 16: 411-417, 2018.

18. Liu XX, Zhang XW, Wang K, Wang XY, Ma WL, Cao W, Mo D, Sun Y and Li XQ: Kuwanon G attenuates atherosclerosis by upregulation of LXR $\alpha-\mathrm{ABCA} 1 / \mathrm{ABCG} 1$ and inhibition of $\mathrm{NF \kappa B}$ activity in macrophages. Toxicol Appl Pharmacol 341: 56-63, 2018.

19. Kuk EB, Jo AR, Oh SI, Sohn HS, Seong SH, Roy A, Choi JS and Jung HA: Anti-Alzheimer's disease activity of compounds from the root bark of Morus alba L. Arch Pharm Res 40: 338-349, 2017.

20. Gong M, Ye S, Li WX, Zhang J, Liu Y, Zhu J, Lv W, Zhang H, Wang J, Lu A, et al: Regulatory function of $\mathrm{Pja} 2$ mediated by the P2rx3/P2rx7 axis in mouse hippocampal neuronal cells. Am J Physiol Cell Physiol 318: C1123-C1135, 2020.

21. Cancela S, Canclini L, Mourglia-Ettlin G, Hernández P and Merlino A: Neuroprotective effects of novel nitrones: In vitro and in silico studies. Eur J Pharmacol 871: 172926, 2020.

22. Xu Y, Wang S, Feng L, Zhu Q, Xiang P and He B: Blockade of PKC-beta protects HUVEC from advanced glycation end products induced inflammation. Int Immunopharmacol 10: 1552-1559, 2010.

23. Xu Y, Feng L, Wang S, Zhu Q, Lin J, Lou C, Xiang P,He B, Zheng Z, Tang D, et al: Phytoestrogen calycosin-7- $O-\beta-\mathrm{D}$-glucopyranoside ameliorates advanced glycation end products-induced HUVEC damage. J Cell Biochem 112: 2953-2965, 2011.

24. Xu Y, Feng L, Wang S, Zhu Q, Zheng Z, Xiang P, He B and Tang D: Calycosin protects HUVECs from advanced glycation end products-induced macrophage infiltration. J Ethnopharmacol 137: 359-370, 2011.

25. Leng J, Li X, Tian H, Liu C, Guo Y, Zhang S, Chu Y, Li J, Wang Y and Zhang L: Neuroprotective effect of diosgenin in a mouse model of diabetic peripheral neuropathy involves the Nrf2/HO-1 pathway. BMC Complement Med Ther 20: 126, 2020.

26. Voehringer DW: BCL-2 and glutathione: Alterations in cellular redox state that regulate apoptosis sensitivity. Free Radic Biol Med 27: 945-950, 1999.

27. Scremin OU, Roch M, Norman KM, Djazayeri S and Liu YY: Brain acetylcholine and choline concentrations and dynamics in a murine model of the Fragile X syndrome: Age, sex and regionspecific changes. Neuroscience 301: 520-528, 2015.

28. Zhou X, Zhu Q, Han X, Chen R, Liu Y, Fan H and Yin X: Quantitative-profiling of neurotransmitter abnormalities in the disease progression of experimental diabetic encephalopathy rat. Can J Physiol Pharmacol 93: 1007-1013, 2015.

29. Liapi C, Kyriakaki A, Zarros A, Galanopoulou P, Al-Humadi H, Dontas I, Voumvourakis K and Tsakiris S: Choline-deprivation alters crucial brain enzyme activities in a rat model of diabetic encephalopathy. Metab Brain Dis 25: 269-276, 2010.

30. Aykac A, Ozbeyli D, Uncu M, Ertaş B, Kılınc O, Şen A, Orun O and Sener G: Evaluation of the protective effect of Myrtus communis in scopolamine-induced Alzheimer model through cholinergic receptors. Gene 689: 194-201, 2019.

31. Argente-Pla M,Pérez-Lázaro A, Martinez-Millana A, Del OlmoGarcía MI, Espí-Reig J, Beney to-Castello I, López-Andújar R and Merino-Torres JF: Simultaneous pancreas kidney transplantation improves cardiovascular autonomic neuropathy with improved valsalva ratio as the most precocious test. J Diabetes Res 2020: 7574628,2020

32. Zhu X, Cheng YQ, Lu Q, Du L, Yin XX and Liu YW: Enhancement of glyoxalase 1, a polyfunctional defense enzyme, by quercetin in the brain in streptozotocin-induced diabetic rats. Naunyn Schmiedebergs Arch Pharmacol 391: 1237-1245, 2018.

33. Lu M, Xu L, Li B, Zhang W, Zhang C, Feng H, Cui X and Gao H: Protective effects of grape seed proanthocyanidin extracts on cerebral cortex of streptozotocin-induced diabetic rats through modulating AGEs/RAGE/NF-kappaB pathway. J Nutr Sci Vitaminol (Tokyo) 56: 87-97, 2010. 
34. Luévano-Contreras C, Gómez-Ojeda A, Macías-Cervantes MH and Garay-Sevilla ME: Dietary advanced glycation end products and cardiometabolic risk. Curr Diab Rep 17: 63, 2017.

35. Singh R, Barden A, Mori T and Beilin L: Advanced glycation end-products: A review. Diabetologia 44: 129-146, 2001.

36. Gurav AN: Advanced glycation end products: A link between periodontitis and diabetes mellitus? Curr Diabetes Rev 9: 355-361, 2013.

37. Shumilina J, Kusnetsova A, Tsarev A, Janse van Rensburg HC, Medvedev S, Demidchik V, Van den Ende W and Frolov A: Glycation of plant proteins: Regulatory roles and interplay with sugar signalling? Int J Mol Sci 20: 2366, 2019.

38. Bellier J, Nokin MJ, Lardé E, Karoyan P, Peulen O, Castronovo V and Bellahcène A: Methylglyoxal, a potent inducer of AGEs, connects between diabetes and cancer. Diabetes Res Clin Pract 148: 200-211, 2019.

39. Dafre AL, Schmitz AE and Maher P: Methylglyoxal-induced AMPK activation leads to autophagic degradation of thioredoxin 1 and glyoxalase 2 in HT22 nerve cells. Free Radic Biol Med 108: 270-279, 2017.

40. Sung SK, Woo JS, Kim YH, Son DW, Lee SW and Song GS: Sildenafil ameliorates advanced glycation end products-induced mitochondrial dysfunction in HT-22 hippocampal neuronal cells. J Korean Neurosurg Soc 59: 259-268, 2016.

41. Li Z, Chen X, Lu W, Zhang S, Guan X, Li Z and Wang D: Anti-oxidative stress activity is essential for Amanita caesarea mediated neuroprotection on glutamate-induced apoptotic HT22 cells and an Alzheimer's disease mouse model. Int J Mol Sci 18 E1623, 2017.

42. Liu J, Li L and Suo WZ: HT22 hippocampal neuronal cell line possesses functional cholinergic properties. Life Sci 84: 267-271, 2009.

43. Singh VP, Bali A, Singh N and Jaggi AS: Advanced glycation end products and diabetic complications. Korean J Physiol Pharmacol 18: 1-14, 2014.

44. Chen F, Nakashima N, Kimura I and Kimura M: Hypoglycemic activity and mechanisms of extracts from mulberry leaves (folium mori) and cortex mori radicis in streptozotocin-induced diabetic mice. Yakugaku Zasshi 115: 476-482, 1995 (In Japanese).

45. Lemus I, García R, Delvillar E and Knop G: Hypoglycaemic activity of four plants used in Chilean popular medicine. Phytother Res 13: 91-94, 1999.

46. Cai S, Sun W, Fan Y, Guo X, Xu G, Xu T, Hou Y, Zhao B, Feng X and Liu T: Effect of mulberry leaf (Folium Mori) on insulin resistance via IRS-1/PI3K/Glut-4 signalling pathway in type 2 diabetes mellitus rats. Pharm Biol 54: 2685-2691, 2016.

47. Samarghandian S, Azimi-Nezhad M and Samini F: Ameliorative effect of saffron aqueous extract on hyperglycemia, hyperlipidemia, and oxidative stress on diabetic encephalopathy in streptozotocin induced experimental diabetes mellitus. BioMed Res Int 2014: 920857, 2014

48. Jiang L, Wang J, Wang Z, Huang W, Yang Y, Cai Z and Li K: Role of the glyoxalase system in Alzheimer's disease. J Alzheimers Dis 66: 887-899, 2018.

49. Joubert M, Manrique A, Cariou B and Prieur X: Diabetes-related cardiomyopathy: The sweet story of glucose overload from epidemiology to cellular pathways. Diabetes Metab 45: 238-247, 2019.

50. Abbas GM, Abdel Bar FM, Baraka HN, Gohar AA and Lahloub MF: A new antioxidant stilbene and other constituents from the stem bark of Morus nigra L. Nat Prod Res 28: 952-959, 2014.

51. Tzavara ET, Bymaster FP, Overshiner CD, Davis RJ, Perry KW, Wolff M, McKinzie DL, Witkin JM and Nomikos GG: Procholinergic and memory enhancing properties of the selective norepinephrine uptake inhibitor atomoxetine. Mol Psychiatry 11: 187-195, 2006.
52. Kumamoto E and Kuba K: Sustained rise in ACh sensitivity of a sympathetic ganglion cell induced by postsynaptic electrical activities. Nature 305: 145-146, 1983.

53. Agatonovic-Kustrin S, Kustrin E and Morton DW: Essential oils and functional herbs for healthy aging. Neural Regen Res 14: 441-445, 2019.

54. Pandey S and Garabadu D: Piracetam facilitates the anti-amnesic but not anti-diabetic activity of metformin in experimentally induced type-2 diabetic encephalopathic rats. Cell Mol Neurobio 37: 791-802, 2017.

55. Song IU, Chung SW, Kim YD and Maeng LS: Relationship between the hs-CRP as non-specific biomarker and Alzheimer's disease according to aging process. Int J Med Sci 12: 613-617, 2015.

56. Gregor MF and Hotamisligil GS: Inflammatory mechanisms in obesity. Annu Rev Immunol 29: 415-445, 2011.

57. Gorska-Ciebiada M, Saryusz-Wolska M, Borkowska A, Ciebiada M and Loba J: Serum levels of inflammatory markers in depressed elderly patients with diabetes and mild cognitive impairment. PLoS One 10: e0120433, 2015.

58. John CM, Mohamed Yusof NIS, Abdul Aziz SH and Mohd Fauzi F: Maternal cognitive impairment associated with gestational diabetes mellitus: A review of potential contributing mechanisms. Int J Mol Sci 19: E3894, 2018.

59. Meng Y, Wang W, Kang J, Wang X and Sun L: Role of the PI3K/ AKT signalling pathway in apoptotic cell death in the cerebral cortex of streptozotocin-induced diabetic rats. Exp Ther Med 13: 2417-2422, 2017.

60. Parveen A, Kim JH, Oh BG, Subedi L, Khan Z and Kim SY: Phytochemicals: Target-based therapeutic strategies for diabetic retinopathy. Molecules 23: E1519, 2018.

61. Liang W, Zhang D, Kang J, Meng X, Yang J, Yang L, Xue N, Gao Q, Han S and Gou X: Protective effects of rutin on liver injury in type 2 diabetic $\mathrm{db} / \mathrm{db}$ mice. Biomed Pharmacother 107: 721-728, 2018.

62. Butterfield DA, Di Domenico F and Barone E: Elevated risk of type 2 diabetes for development of Alzheimer disease: A key role for oxidative stress in brain. Biochim Biophys Acta 1842: 1693-1706, 2014

63. Han S, Gao H, Chen S, Wang Q, Li X, Du LJ, Li J, Luo YY, Li JX, Zhao LC, et al: Procyanidin A1 Alleviates Inflammatory Response induced by LPS through NF- $\mathrm{kB}$, MAPK, and Nrf2/ HO-1 Pathways in RAW264.7 cells. Sci Rep 9: 15087, 2019.

64. Xu L, Botchway BOA, Zhang S, Zhou J and Liu X: Inhibition of NF- $\mathrm{NB}$ signaling pathway by resveratrol improves spinal cord injury. Front Neurosci 12: 690, 2018.

65. Ghosh S and Hayden MS: New regulators of NF-kappaB in inflammation. Nat Rev Immunol 8: 837-848, 2008.

66. Youdim KA, Qaiser MZ, Begley DJ, Rice-Evans CA and Abbott NJ: Flavonoid permeability across an in situ model of the blood-brain barrier. Free Radic Biol Med 36: 592-604, 2004.

67. Youdim KA, Dobbie MS, Kuhnle G, Proteggente AR, Abbott NJ and Rice-Evans C: Interaction between flavonoids and the bloodbrain barrier: In vitro studies. J Neurochem 85: 180-192, 2003.

68. Bogush M, Heldt NA and Persidsky Y: Blood brain barrier injury in diabetes: Unrecognized effects on brain and cognition. J Neuroimmune Pharmacol 12: 593-601, 2017.

This work is licensed under a Creative Commons Attribution-NonCommercial-NoDerivatives 4.0 International (CC BY-NC-ND 4.0) License. 